TECHNICAL NOTE

\author{
S.H. Cekirge \\ K. Yavuz \\ S. Geyik \\ I. Saatci
}

\section{HyperForm Balloon-Assisted Endovascular Neck Bypass Technique to Perform Balloon or Stent- Assisted Treatment of Cerebral Aneurysms}

SUMmARY: We describe a technique to bypass aneurysm neck using the HyperForm balloon to perform balloon- or stent-assisted endovascular treatment of complex large or giant aneurysms with very wide neck in which other methods would fail to obtain an access distal to the aneurysm.
$\mathbf{R}_{\mathrm{p}}^{\mathrm{e}}$ ecent endovascular strategies in the management of complex aneurysms with wide or fusiform neck include balloon remodeling, ${ }^{1}$ use of intravascular stents ${ }^{2}$ combined with coils or liquid embolic (Onyx; ev3, Irvine, Calif) to reconstruct the parent artery, ${ }^{1-5}$ and, most recently, exclusion of cerebral aneurysms from the circulation using covered stents. ${ }^{6}$ However, in cases with complex fusiform or very wide aneurysm neck configuration, acute angle formed by the aneurysm with the parent artery, or tortuosity of the parent artery itself, negotiation of the aneurysm neck to place a balloon or stent across it is one of the main difficulties leading technical failures. $^{7}$ We describe the "balloon-assisted endovascular neck bypass technique" for difficult aneurysms in which primary bypassing has failed for placing the balloon or stent across the aneurysm neck to perform balloon- or stent-assisted treatment.

\section{Technique}

A $6 \mathrm{~F}$ guiding catheter is introduced into the proximal parent artery at which the complex aneurysm is located. After the decision is made about the endovascular treatment approach, which is either with balloon- or stent-assisted treatment, bypassing the aneurysm neck is attempted either with the HyperForm or HyperGlide balloon catheter and X-Pedion 0.010 inch guidewire (ev3) or 0.012 inch Glidewires (Terumo, Tokyo, Japan) with different tip shapes or regular microcatheters with different choices of wires. If the primary negotiation of a balloon catheter with its wire or a microcatheter to exchange with stent deployment system across the aneurysm neck fails, HyperForm balloon-assisted endovascular neck bypass technique is used. In this technique, a HyperForm balloon with X-Pedion 0.010 or Glidewire 0.012 microguidewire is advanced into the aneurysm gently and pushed forward all along the inner wall of the aneurysm until it makes a loop inside the aneurysm to reach the outflow of the aneurysm and then into the parent artery distal to the aneurysm. The HyperForm balloon is then advanced over the wire and placed distal to the aneurysm. To flatten the looped balloon catheter to position it bridging the neck of the aneurysm without losing the access, the balloon that has been placed distal to the aneurysm is gently inflated to stabilize it, and then the balloon microcatheter is pulled very slowly to remove the slackened part within the aneurysm sac. Because the balloon is inflated distally, it does not move while its loop inside the aneurysm gets

Received February 19, 2007; accepted March 14.

From the Department of Radiology, Hacettepe University, Ankara, Turkey.

Address correspondence to Kivilcim Yavuz, Radiology, Hacettepe University Hospitals Sihhiye, Ankara 06520. Turkey; e-mail: kivilcimyvz@yahoo.com

DOl 10.3174/ajnr.A0618 straightened by gently pulling the balloon catheter. The balloon is then deflated. One can then either use the same balloon for balloonassisted treatment by pulling it down to the level of the aneurysm neck, or a longer HyperGlide balloon can be replaced exchanging over a X-Celerator 0.010-inch, 300-cm wire (ev3) for balloon-assisted coiling or Onyx treatment. If stent placement is to be performed, an Echelon 10 microcatheter (Ev3) is replaced distal to the aneurysm over X-Celerator 0.010-inch, 300-cm wire placed through the HyperForm balloon catheter, which has been used to bypass the aneurysm neck. Then, a 0.014-inch, 300-cm exchange wire can be introduced through the Echelon 10 microcatheter to accomplish the navigation of the stent delivery system at the aneurysm neck. Therefore, once the aneurysm neck is bypassed, the treatment of the aneurysm can be pursued with balloon- or stent-assisted coil/Onyx packing or by using a covered stent exclusively. This technique is named after the HyperForm balloon, because it should be the choice of balloon as it is less traumatic due to its high compliance and has much better navigation ability than other balloons over the looped wire inside the aneurysm sac due to its shorter balloon length.

\section{Illustrative Case Notes}

\section{Case 1}

Balloon-assisted treatment followed by possible stent placement was considered in a 50-year-old woman with a giant wide-necked internal carotid artery (ICA) aneurysm. The aneurysm had a complex configuration showing an acute angle with the parent artery. A HyperForm balloon with a X-Pedion guidewire was advanced. First, primary bypass of the aneurysm neck was attempted with X-Pedion guidewire and hydrophilic microguidewires (Terumo) with different tip angles; however, a guidewire could not be navigated distal to the aneurysm neck. As described above, the X-Pedion wire was looped within the aneurysm sac, and the balloon was advanced over the wire distal to the aneurysm and used to straighten the loop. A HyperForm balloon catheter was exchanged with a HyperGlide balloon catheter over an X-Celerator 0.010-inch, 300-cm wire. The aneurysm was occluded using a balloon-assisted coil and Onyx combination, ${ }^{7}$ and then a selfexpandable stent was placed across the neck to prevent future recanalization (Fig 1).

\section{Case 2}

A 32-year-old woman with a giant wide-necked ICA aneurysm was scheduled for endovascular treatment using a covered stent. Primary bypassing of the aneurysm neck failed despite using different kinds of microguidewires and microcatheters. Using the technique described above, a HyperForm balloon catheter, which was exchanged with an Echelon microcatheter over an X-Celerator 0.010-inch, 300-cm wire, 

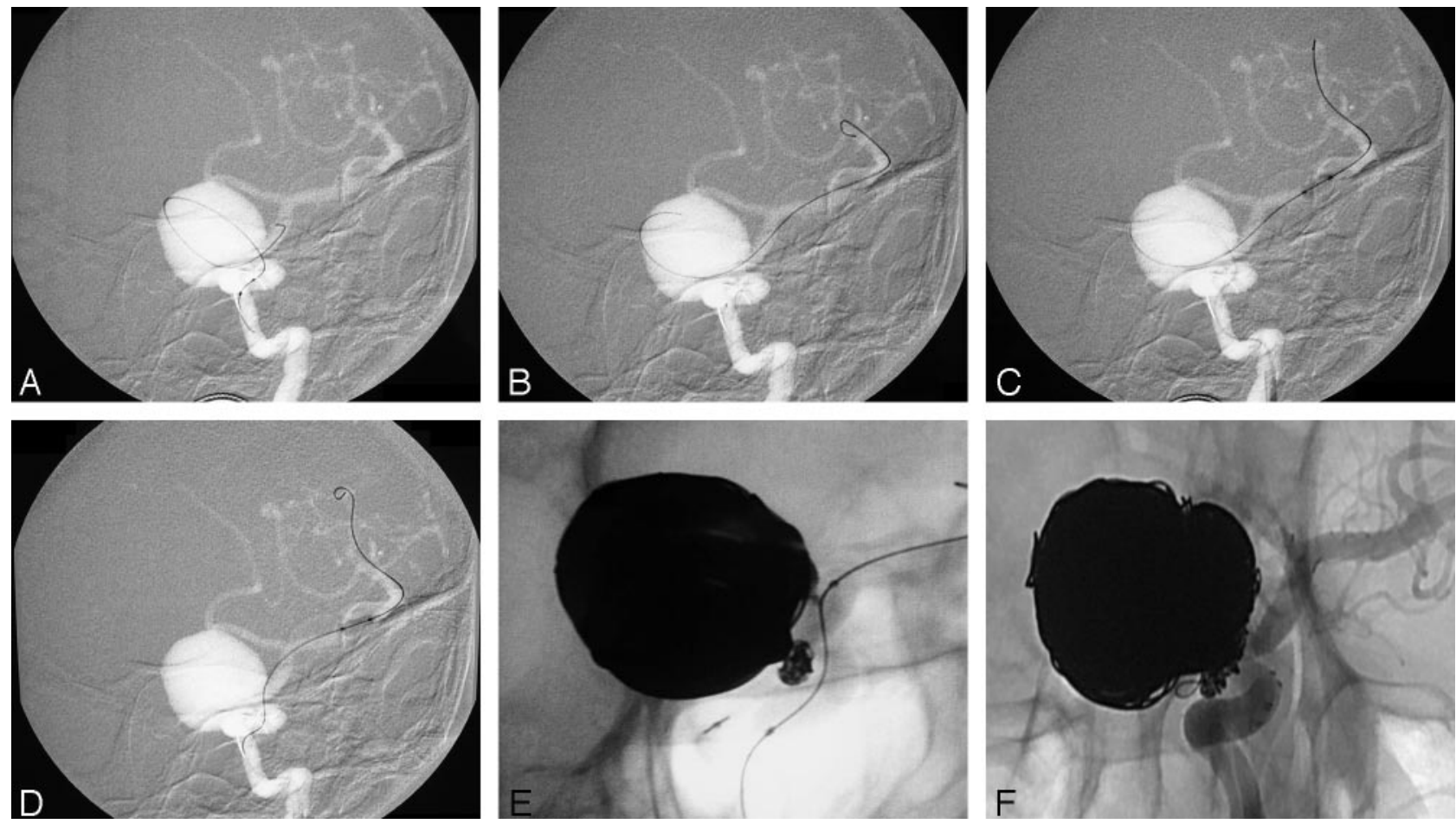

Fig 1. $A-D$, Roadmap images of the giant ICA aneurysm showing the steps of the balloon-assisted bypass technique.

$A$, The guidewire of the balloon is shown making a loop inside the aneurysm sac.

$B$, Placement of the guidewire distal to the aneurysm in the middle cerebral artery.

$C$, Inflation of the HyperForm balloon placed over the looped wire is demonstrated.

$D$, Image showing the straightening of the looped wire inside the aneurysm sac while the balloon is inflated.

$E$, Nonsubtracted image after the balloon-assisted coil-Onyx combination treatment of the aneurysm.

$F$, Posttreatment image shows the stent placed at the neck of the aneurysm at the end of the balloon-assisted embolization procedure.

was placed distal to the aneurysm neck. Then, for a stronger support, a stiffer 0.014-inch, 300-cm exchange wire was introduced through the Echelon 10 microcatheter. Over this wire, a balloon-expandable stent-graft $(5 \times 27 \mathrm{~mm}$, Jostent-Graftmaster; Abbott, Hoofddorp, The Netherlands) was advanced and deployed successfully at the aneurysm neck, excluding the aneurysm from the circulation (Fig 2).

\section{Discussion}

Endovascular treatment of wide-necked, complex, and large or giant aneurysms with preservation of the parent artery still remains a challenge. Advanced endovascular techniques, such as balloon remodeling, ${ }^{1}$ intravascular stent-assisted treatment combined with coils or liquid embolic, intrasaccular coil and Onyx combination, and covered stent placement, have been developed to provide more efficient and durable results in the long term. ${ }^{2,3,5,6,8,9}$

Lubicz et $\mathrm{al}^{7}$ published their experience with 16 consecutive wide-necked intracranial aneurysms using HyperForm balloon remodeling and reported failure of balloon positioning in 4 patients. They used a stiffer microguidewire to bypass these aneurysms and then exchanged with the X-Pedion wire for balloon inflation. Szikora et $\mathrm{al}^{10}$ also reported access failure with a rate of $11 \%$ in their series with balloon-expandable stents.

However, in difficult aneurysms with a very complex neck configuration, primary bypass of the aneurysm neck using any kind of microguidewires or microcatheters may also fail. Proximal acute-angled loops of the parent artery make these cases even more difficult, because they reduce the guidewire torquability. In such settings, we have found HyperForm balloonassisted endovascular neck bypass technique very useful in the ability to treat complex aneurysms.

Using this technique in large/giant complex aneurysms, we have not experienced any complication. We think that the 2 important steps of the technique are advancing the HyperForm balloon over the looped wire inside the aneurysm to achieve the distal access and removing the slackened part of it when the balloon is distally inflated. In the former, placing the guiding catheter as high as possible before advancing the balloon over the wire would increase the ease of this step. In the latter, inflating the balloon very gently but enough to hold itself stable in the vessel is essential. The movement of the balloon in this step may cause not only the technical failure but also vessel dissection when it is pulled to straighten the slackened part. Therefore, the level of inflation causing a flow arrest in the artery is thought to be the optimum, because it provides immobility of the inflated balloon. The HyperForm balloon is recommended to be the material of choice, because its short length and high compliancy provide not only superior navigation in the first step but also safety in the second step of the technique.

In conclusion, this technique allows balloon or stent placement across the aneurysm neck and, thus, enables us to perform the endovascular treatment of complex aneurysms in which conventional techniques have failed to access distal to the aneurysm. 

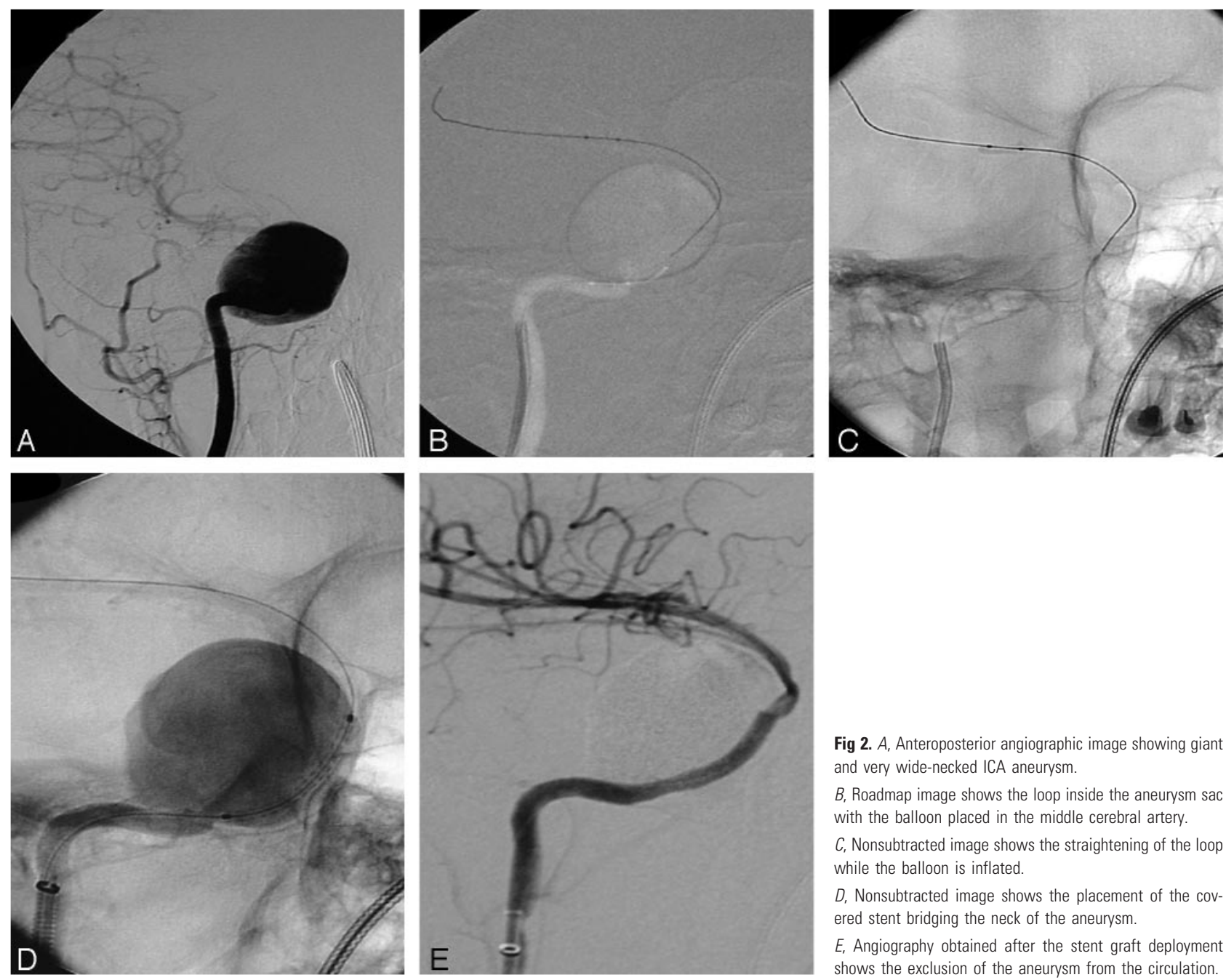

Fig 2. A, Anteroposterior angiographic image showing giant and very wide-necked ICA aneurysm.

$B$, Roadmap image shows the loop inside the aneurysm sac with the balloon placed in the middle cerebral artery.

C. Nonsubtracted image shows the straightening of the loop while the balloon is inflated

$D$, Nonsubtracted image shows the placement of the covered stent bridging the neck of the aneurysm.

E, Angiography obtained after the stent graft deployment shows the exclusion of the aneurysm from the circulation.

\section{References}

1. Moret J, Cognard C, Weill A, et al. Reconstruction technique in the treatment of wide-neck intracranial aneurysms: long-term angiographic and clinical results-apropos of 56 cases. J Neuroradiol 1997;24:30-44

2. Higashida RT, Smith W, Gress D, et al. Intravascular stent and endovascular coil placement for a ruptured fusiform aneurysm of the basilar artery: case report and review of the literature. J Neurosurg 1997;87:944-49

3. Cekirge HS, Saatci I, Ozturk MH, et al. Late angiographic and clinical follow-up results of 100 consecutive aneurysms treated with Onyx reconstruction: largest single-center experience. Neuroradiol 2006;48: 113-26

4. Molyneux AJ, Cekirge S, Saatci I, et al. Cerebral Aneurysm Multicenter European Onyx (CAMEO) trial: results of a prospective observational study in 20 European centers. AJNR Am J Neuroradiol 2004;25:39-51

5. Mawad ME, Cekirge S, Ciceri E, et al. Endovascular treatment of giant and large intracranial aneurysms by using a combination of stent placement and liquid polymer injection. J Neurosurg 2002;96:474-82

6. Saatci I, Cekirge HS, Ozturk MH, et al. Treatment of internal carotid artery aneurysms with a covered stent: experience in 24 patients with mid-term follow-up results. AJNR Am J Neuroradiol 2004;25:1742-49

7. Lubicz B, Leclerc X, Gauvrit JY, et al. HyperForm remodeling-balloon for endovascular treatment of wide-neck intracranial aneurysms. AJNR Am J Neuroradiol 2004;25:1381-83

8. Cekirge S, Saatci I. Advanced reconstructive endovascular techniques for the treatment of cerebral aneurysms. Neurol Res 2005;27(suppl 1):108-15

9. Cekirge HS, Saatci I, Geyik S, et al. Intrasaccular combination of metallic coils and Onyx liquid embolic agent for the endovascular treatment of cerebral aneurysms. J Neurosurg 2006;105:706-12

10. Szikora I, Berentei Z, Kulcsar Z, et al. Endovascular treatment of intracrania aneurysms with parent vessel reconstruction using balloon and self expandable stents. Acta Neurochir 2006;148:711-23 